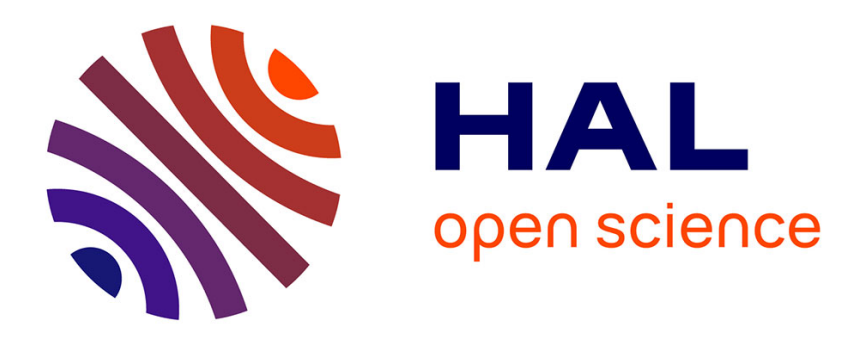

\title{
Mutual Supervision in Preshipment Inspection Programs
}

Vianney Dequiedt, Anne-Marie Geourjon, Grégoire Rota-Graziosi

\section{To cite this version:}

Vianney Dequiedt, Anne-Marie Geourjon, Grégoire Rota-Graziosi. Mutual Supervision in Preshipment Inspection Programs. 2011. halshs-00554316

\section{HAL Id: halshs-00554316 \\ https://shs.hal.science/halshs-00554316}

Preprint submitted on 10 Jan 2011

HAL is a multi-disciplinary open access archive for the deposit and dissemination of scientific research documents, whether they are published or not. The documents may come from teaching and research institutions in France or abroad, or from public or private research centers.
L'archive ouverte pluridisciplinaire HAL, est destinée au dépôt et à la diffusion de documents scientifiques de niveau recherche, publiés ou non, émanant des établissements d'enseignement et de recherche français ou étrangers, des laboratoires publics ou privés. 


\title{
Mutual Supervision in Preshipment Inspection Programs
}

\author{
Vianney Dequiedt,$^{\ddagger}$ Anne-Marie Geourjon, ${ }^{\ddagger}$ \\ and Grégoire Rota Graziosi ${ }^{\ddagger}$ \\ †: CERDI-CNRS, Université d'Auvergne, \\ 65 boulevard François Mitterrand, 63000 Clermont-Ferrand, France \\ Corresponding author: vianney.dequiedt@u-clermont1.fr
}

November 30, 2009 


\begin{abstract}
Preshipment inspection programs are implemented in many developing countries to fight customs corruption. They consist in delegating the inspection of imports to a private firm that operates in the exporting country. To study those PSI programs, we develop a hierarchical agency model where the government authority can rely on two supervisors, namely the private inspection firm and the customs administration, to control importers' declarations. The government's optimal program is fully characterized. We devote some attention to the optimal inspection policy and its comparative statics properties. In particular, we identify the situations in which PSI programs are optimal. Our results highlight the fact that implementing PSI programs both to fight corruption and to modernize customs is inconsistent. We also discuss the optimal reconciliation policy, i.e. what to do in case of conflicting inspection reports by the private firm and the customs administration. In the optimal mechanism, mutual supervision between the private firm and the customs administration is used to provide adequate incentives to all parties.
\end{abstract}

JEL Codes: D82, F13, L33.

Keywords: Preshipment inspection, Mutual supervision, Corruption, Customs administration. 


\section{Introduction}

In many developing countries, customs revenues are an important source of public financial ressources. However, in those countries customs tariff collection is suspected to be particularly inefficient. Several factors may explain this inefficiency. Most of developing countries encounter major difficulties in controlling porous borders. Despite ambitious reforms to modernize customs, administrative capacities in those countries are still weak and ex post controls ineffective. In addition, it is acknowledged that corruption of customs administrations is widespread and costs a non-negligeable share of potential customs revenues. More generally, customs environment has a significant impact on trade flows and economic well-being. ${ }^{1}$

Frequently encouraged by international institutions, some countries resorted to PreShipment Inspection (PSI) programs to improve the efficiency of tariff collection, and in particular to fight customs administration corruption. ${ }^{2}$ Those programs consist in delegating an inspection of imports to a private surveillance company (the PSI firm) at embarkation ports or airports or in the exporting firms' premises or even at destination. Pre-shipment inspection complements information provided in customs declarations and can be used to evaluate customs duties. This additional information should limit the discretionary power of customs officers and thus be an efficient mean of reducing customs corruption.

The aim of this paper is to build a simple theoretical model that captures the essential ingredients of PSI programs and that can be exploited to derive normative implications for their design. We formalize the relationship between the four different parties which are concerned by those programs, namely the government, the customs administration, the PSI firm and the importer. In the spirit of Tirole (1986) (see also Tirole (1992)), we

\footnotetext{
${ }^{1}$ See Wilson, Mann, and Otsuki (2005) and the World Bank Working Papers by Hoekman and Nicita (2008) and Njinkeu, Wilson, and Powo Fossa (2008) for further details.

${ }^{2}$ See the World Bank discussion paper by Low (1995) for a general presentation.
} 
develop a model of hierarchical agency with two supervisors to capture the interactions between preshipment inspection and customs administration inspection. Equipped with this model, we discuss properties of the optimal inspection policy (i.e. when to inspect and who should inspect imports) and of the optimal reconciliation policy (i.e. what to do in case of conflicting pieces of information). The incentives at stake in preshipment inspection serve to illustrate some mechanics of mutual supervision in hierarchical agency.

The first PSI program was implemented in Democratic Republic of Congo (Zaire) in 1963. It was then followed by more than fifty countries over the world (see Tables 1 and 2). At the beginning, the main objective of PSI programs was to reduce capital evasion through overinvoicing. As capital controls progressively disappeared, the objectives of PSI programs changed. They more and more became an intrument to fight import-tariff evasion. Still today and despite fiscal transition, ${ }^{3}$ customs declarations remain crucial for developing countries because most of final consumption goods are imported and thus most of the VAT is collected at the border.

In contrast with their importance for the concerned developing countries, the academic literature on PSI issues remains very restricted. Only few papers focus directly on PSI programs: Johnson (2001), Anson, Cadot, and Olarreaga (2006), Yang (2008) and Yang (2009). Apart from the notable exception of Anson, Cadot, and Olarreaga (2006) which we further discuss below, those papers are empirical and evaluate the profitability of PSI programs. Clearly, PSI programs can help improving tax collection through outsourcing to the private sector: the private firm (the PSI firm) contributes to the definition of the tax base. ${ }^{4}$ In this spirit, Yang (2008) considers that PSI programs are one way to "hire in-

\footnotetext{
${ }^{3}$ Fiscal transition consists in reducing import tariffs and increasing revenues from domestic taxation such as Value Added Tax

${ }^{4}$ The partial privatization of tax collection is not new. Tax farming in France before the 1789 Revolution is certainly the most famous example. It may be usual even today in developed countries : For instance, in 2006, the Internal Revenue Service (IRS) planed to outsource the collection of some private debts (in fact, 12500 taxpayers whom owes $\$ 25000$ or less in back taxes) to three private companies (see "IRS Enlists Help in Collecting Delinquent Taxes," The New York Times, August 20, 2006).
} 
tegrity" from the private sector. He concludes that these programs increased import duties by $15-30 \%$ during the first five years. On the other hand, Anson, Cadot, and Olarreaga (2006) obtain less clear-cut results and according to their estimations, PSI programs may decrease (in the case of the Philippines) or increase (in the case of Argentina) fraud. More generally, PSI programs certainly deserve some attention because they permit a renewed analysis of the interactions between tax evasion, corruption and enforcement rules. ${ }^{5}$

Behind the common designation, there is a great diversity in PSI programs. For instance, in some countries importers have to pay for the PSI services, in others, it is the government itself. The authority that mandates a PSI may be the Ministry of Finance (Angola, Chad, Congo...), the Ministry of Trade (Côte d'Ivoire), the Central Bank (Iran) or the Institute of Standards and Metrology (Jordan). The price of the PSI service varies although it is usually based on the f.o.b value of imports and fixed between 0.5 and $0.8 \%$ of this value. Reconciliation practices (i.e. what is done in case the different pieces of information conflict and who does it?) also differ. Actually, reconciliation policy is mostly unsuccessful even if it is generally included in PSI contracts. ${ }^{6}$ There have been some experiences - in Mauritania for instance - of reconciliation by a high level steering committee of the Ministry of Finance using data provided by the PSI company and customs administration. Unfortunately, these experiences remain sporadic and Ministers in charge

\footnotetext{
${ }^{5}$ These interactions have been highlighted for a long time in empirical work. For instance, Bhagwati (1964) established that the discrepancies between a country's reported imports and the corresponding exports reported by its trading partners may be explained by opportunistic undervaluation or misclassification of imports at the border in order to reduce the tariff burden (see also De Wulf (1981)). Pritchett and Sethi (1994) analyse the relation between the revenues collected and the official rates of taxation in some developing countries (Jamaica, Kenya, and Pakistan). They compare the statutory ad valorem tariff rates (official rates) with the ratio of tariff revenues to import values (collected rates). They highlight that the collected rate is weakly related to the official rate. More recently, Fisman and Wei (2004) focus on evasion in China's imports from Hong Kong at a higher level of disaggregation than the preceding paper. They study empirically how tax evasion responds to tax rates, and they show a strong positive relationship between these: products taxed at higher rates are more prone to be affected by evasion.

${ }^{6}$ There are two main reasons for this. First, the lack of computer connection between the different parties makes data crosschecking difficult. Second, it is hard to compare the two informations since the goods listed on the certificate issued by the PSI firm may be imported in separate shipments and generate several customs declarations.
} 
of import verification programs are still reluctant to undertake concrete follow up actions.

As the whole literature on contract theory suggests (see for instance Laffont and Martimort (2001) or Bolton and Dewatripont (2005)), it is likely that the details of the design affect the efficiency of a whole program. However, in order to identify the good practices, an empirical strategy seems inappropriate because available data are insufficient. This leads us to adopt a theoretical perspective and construct a simple model of PSI programs.

We use a hierarchical agency framework in which the regulator (i.e. the government authority which acts as a Principal) may employ two different supervisors, the PSI firm and the customs administration, to control the declaration of imports by an agent (the importing firm). Our model captures the following four central elements: $(i)$ the regulator must deal with asymmetric information as the agent knows more than he does about the value of imports; (ii) the agent is opportunist and will underdeclare if the fear of being detected is not strong enough; (iii) the customs administration can inspect imported goods but the customs officer in charge of this control may be corrupt and enter a sideagreement with the agent; $(i v)$ the PSI firm can also inspect the imports. This firm is not subject to corruption with other parties but is nevertheless subject to opportunistic behavior and will not hesitate to make false reports if it is in its interest to do so. ${ }^{7}$

\footnotetext{
${ }^{7}$ The no corruption assumption may be questionnable but is standard in the PSI litterature. Johnson (2001), for instance, argues:

"Normally, given their geographical separation, there is little contact between customs authorities and PSI agents, thereby making collusion between them extremely costly. Also, in a competitive environment, the PSI company is highly dependent upon maintaining a good reputation and, therefore, has strong incentives to avoid corrupt activities (such as colluding with the importer or government officials)."
}

We agree with the argument against corruption of PSI firms, but do not take for granted that reputation is a sufficiently strong disciplining force. Indeed, the market for PSI services is oligopolistic: only four multinational firms share more than $90 \%$ of the market, which may be estimated to more than 650 millions dollars in 2007 (see Table 3). Moreover, PSI programs are known to be transitory: they will not last forever. As a consequence, reputation as a disciplining force may not work properly. Therefore, we assume that PSI firms are opportunist and must be given adequate incentives. 
When studying corruption in customs administration, we abstract from the problem of extortion practices and concentrate on the problem of underinvoicing. It is plausible that doing so underestimates the benefits of a PSI program because, by limiting the discretionary power of the customs officers, PSI certainly makes extortion more difficult. However, our optimal inspection policy for PSI programs does not call for inspection by the customs administration on the equilibrium path: it is also the optimal way to fight extortion.

Our model is reminiscent of double supervision models developed by Kofman and Lawarree (1993), Mishra and Anant (2006) or Bac and Bag (2006). Following those papers, we study the interaction between a collusive and a non-collusive supervisors. However, to take into account specific aspects of PSI programs, we are led to consider a timing that slightly differs from the one considered in those models. In our special context, the non-collusive supervisor (the PSI firm) intervenes first, before the collusive supervisor (i.e. the customs administration).

Our results stress the importance of commitment by the regulator to an inspection and a reconciliation policy. The benefits of commitment are well known in the agency literature but it is worth emphasizing them in our context as it seems that many countries decide, if not inspection at least reconciliation, ex post. We also stress that the optimal reconciliation policy must solve a double adverse selection problem and must be designed to provide adequate incentives both to the agent and to the PSI firm. It is clearly suboptimal to always trust one party and mutual supervision is key to discipline both supervisors.

Anson, Cadot, and Olarreaga (2006) propose a different model to study PSI programs. They focus on the moral hazard aspect of customs inspection while our model is a pure adverse selection one. Their game theoretic model is aimed at being positive and providing testable implications. Our approach uses contract theory and is more normative. As a 
consequence, their model and ours are complementary and can be used to address different questions.

The paper is organized as follows. In section 2, we construct step by step our model of PSI programs and discuss several useful benchmark cases. Section 3 is devoted to the characterization of the optimal program. There we derive the optimal probabilities of inspection when a PSI firm is used and compare the payoff of the regulator to what he can obtain in the absence of a PSI firm. We also compare the different reconciliation policies that the regulator can implement and their impact on the inspection costs. Section 4 concludes.

\section{The Model}

\subsection{An adverse selection model of corrupt customs administra- tions}

The model is built on a simple version of Principal-Supervisor-Agent models that were developped following the pioneering contribution of Tirole (1986). A government authority or regulator, denoted $R$, is supposed to collect customs duties from an importing firm, denoted $A$. These duties are proportional to the quantity of good $q$, which can be thought of equivalently as the imports value. The duties are fixed at a level $\alpha q$ where $\alpha$ is the tariff rate. The true quantity $q$ is the firm's private information and we assume that it takes value in $\{\underline{q}, \bar{q}\}$. We denote $\Delta q=\bar{q}-\underline{q}$. The firm's decision to import the good is influenced by many factors, like the size of the market, the business cycle, etc... that are outside our simple model and we assume therefore that $q=\bar{q}$ (respectively $q=\underline{q}$ ) with an exogenous probability $\nu$ (resp. $1-\nu$ ) that is common knowledge. Our model is one with adverse selection. All parties are risk neutral.

\section{Complete information}


Under complete information, i.e. when the regulator observes the true $q$, customs duties collection is a trivial task and the regulator obtains a transfer equal to

$$
\Pi_{R}^{C}=\alpha(\nu \bar{q}+(1-\nu) \underline{q})
$$

\section{Incomplete information and no supervision}

Under incomplete information, i.e. when the regulator does not observe the true $q$, customs duties collection is more problematic because of the importer's opportunistic behavior. Absent any supervisory inspection, $A$ would minimize tariff payment and would always declare $\underline{q}$ because the regulator is unable to verify the firm's declaration. In that case, the regulator would collect

$$
\Pi_{R}^{I}=\alpha \underline{q}<\Pi_{R}^{C}
$$

Underinvoicing would dramatically reduce tariff collection by the regulator. This benchmark play some role in the analysis that follows and we refer to it as the no inspection policy.

\section{Uncorrupted supervision}

To avoid underinvoicing and enforce the collection of customs duties, the regulator employs the customs administration, which is modelled as a single supervisor $S_{1}$. Upon receiving $A$ 's customs declaration $\tilde{q}$, the regulator can ask $S_{1}$ to inspect the merchandises. At a cost $c_{1}, S_{1}$ will learn the true value $q$ and must be reimbursed for those inspection costs by the regulator. When the customs administration is uncorrupted, the information obtained by $S_{1}$ is truthfully transmitted to the regulator. If the report of the customs officer differs from the imports declaration, the regulator can impose a fine $F_{A}$ on the importing firm. To be effective the fine must be such that $F_{A}>\alpha \Delta q$ : the regulator must impose a penalty to the frauding firms in addition to the payment of truthful duties. This is what 
we assume in the following.

In that situation, customs administration inspection is used to discipline the firm and the probability of inspection must be adjusted to provide incentives for truthful declaration. Let us denote $p_{1}(\cdot)$ the contingent probability of inspection. Of course, costly inspection is unnecessary when the report of the firm $\tilde{q}$ is equal to $\bar{q}:$ in equilibrium, $p_{1}(\bar{q})=0$. Now we denote $p_{1}(\underline{q})=p_{1}$.

Incentive compatibility for the firm's declaration imposes

$$
\alpha \Delta q \leq p_{1} F_{A}
$$

where the left hand side is the profit of misreporting, while the right hand side is the expected cost of doing so. Because inspection is costly, this incentive constraint is binding in a truthful equilibrium and the regulator optimally sets

$$
p_{1}=\frac{\alpha \Delta q}{F_{A}}
$$

The equilibrium probability of inspection $p_{1}$ is increasing in the tariff rate $\alpha$ and decreasing in the fine that can be imposed on the firm $F_{A}$. However, whether the regulator prefers inducing a truthful declaration or accepting equilibrium underinvoicing depends on the cost $c_{1}$ of inspection. The expected profit of the regulator is

$$
\Pi_{R}^{U}=\max \left\{\Pi_{R}^{I} ; \Pi_{R}^{C}-(1-\nu) \frac{\alpha \Delta q}{F_{A}} c_{1}\right\}
$$

where $\Pi_{R}^{I}$ and $\Pi_{R}^{C}$ are as defined in equations (1) and (2). From this expression we can define a threshold for $c_{1}$ over which the regulator prefers to let underinvoicing occur in 
equilibrium. This threshold $\bar{c}_{1}$ does not depend on the tariff rate $\alpha$ and is given by

$$
\bar{c}_{1}=\frac{\nu}{1-\nu} F_{A}
$$

\section{Corrupt supervision}

As argued before, the hypothesis of an uncorrupted customs administration is not suitable for most countries that implement a PSI program. We now introduce corruption in our simple model. We still assume that the customs administration $\left(S_{1}\right)$ is paid according to a fixed wage that reimburses its $\operatorname{costs} c_{1} \cdot{ }^{8}$ However, we consider now that $S_{1}$ may be corruptible. Specifically, with probability $(1-s)$, the customs officer that controls the merchandise is honest and sends to the regulator the true value $q$ that he observed. With probability $s$, the customs officer is dishonest and colludes with the firm $A .{ }^{9}$ Collusion is valuable for the importing firm-customs officer coalition when the firm declared $\tilde{q}=\underline{q}$ while the true value, observed by the officer, is $q=\bar{q}$. In that case, we assume that bargaining between the firm and the officer takes place under complete information and is Pareto efficient.

Let us denote $b_{1}$ the parameter that captures the bargaining power of the customs officer, which may depend for instance on the perishability of the product or on the cost related to the time release of the merchandise. The firm can secure a $\underline{q}$ report from the officer by paying him $b_{1} \alpha \Delta q$ which is to be compared to the fine $F_{A}$. In the following we assume that $b_{1} \alpha \Delta q<F_{A}{ }^{10}$

The timing of events is given below :

\footnotetext{
${ }^{8}$ We discuss other types of wage schedules at the end of this subsection.

${ }^{9}$ This is a shortcut. The rationale can be that the regulator imposes a constant fine $F_{S_{1}}$ to corrupt officers, and that heterogeneous officers differ in their evaluation of this fine. A proportion $1-s$ considers the fine sufficient and prefer not to enter collusive agreements. A proportion $s$ considers it is worth being corrupt.

${ }^{10}$ The parameter $b_{1}$ is therefore taken in the range $\left[0, \frac{F_{A}}{\alpha \Delta q}\right]$ where $\frac{F_{A}}{\alpha \Delta q}>1$. If it were not the case, the importing firm would anticipate an hold up problem and would never underinvoice.
} 
- At date $t=0$, the firm $A$ learns its type $q$.

- At date $t=1, A$ declares $\tilde{q}$ to $R$.

- At date $t=2$, with probability $p_{1}(\tilde{q}), S_{1}$ inspects the merchandises.

- At date $t=3, S_{1}$ and $A$ may collude.

- At date $t=4, S_{1}$ sends a report $\tilde{q}_{1}$ to $R$.

- At date $t=5$, transfers take place.

The unique tool that is available to the regulator is still the probability of inspection $p_{1}(\cdot)$. Of course, in our two-type model, there is no equilibrium inspection when the firm declares $\tilde{q}=\bar{q}$ and we still denote $p_{1}=p_{1}(\underline{q})$. Let us write the incentive compatibility constraint of a $\bar{q}$-firm. In order to prevent the importing firm from declaring $\underline{q}$, the probability of being inspected must satisfy

$$
\alpha \Delta q \leq p_{1}\left((1-s) F_{A}+s b_{1} \alpha \Delta q\right)
$$

The left hand side of this equation characterizes again the potential gains of the firm from undervoicing (declaring $\underline{q}$ instead of the truthful report $\tilde{q}=\bar{q}$ ). The right hand side is the expected cost of doing so : if it is inspected, which occurs with probability $p_{1}$, the firm must pay $F_{A}$ if the customs officer is honest, which occurs with probability $1-s$, while it must pay the bribe $b_{1} \alpha \Delta q$ if the officer is dishonest $(s)$.

At the optimal truthful equilibrium, the regulator minimizes the inspection costs subject to the incentive constraint and sets:

$$
p_{1}=\frac{\alpha \Delta q}{F_{A}-s\left(F_{A}-b_{1} \alpha \Delta q\right)}
$$

which is an increasing function of $s$, the degree of corruption of the customs administration. With a more corrupt customs administration, it is necessary to inspect imports more often, so that the probability of being inspected by an honest officer is high enough. 
It is possible to determine whether it is worth providing incentives for truthful declaration by comparing $\Pi_{R}^{I}$ and $\Pi_{R}^{C}$ minus the expected cost of inspection.

Proposition 1 When the regulator can only use a corrupt customs administration to collect duties, his payoff is

$$
\Pi_{R}=\max \left\{\Pi_{R}^{I} ; \Pi_{R}^{C}-(1-\nu) \frac{\alpha \Delta q}{F_{A}-s\left(F_{A}-s b_{1} \alpha \Delta q\right)} c_{1}\right\}
$$

$>$ From this expression we can compute the threshold $\hat{c}_{1}$ over which the regulator prefers to let underinvoicing occur in equilibrium. This threshold $\hat{c}_{1}$ depends now on the tariff rate $\alpha$. It is given by

$$
\hat{c}_{1}=\frac{\nu}{1-\nu}\left(F_{A}(1-s)+s b_{1} \alpha \Delta q\right) .
$$

Notice that it is increasing in the tariff rate $\alpha$ and decreasing in the degree of corruption of the customs administration $s$. We can state the same property differently and isolate $s$ instead of $c_{1}$. Doing so, we identify a threshold in the corruptibility of the customs administration above which the regulator prefers to implement the no inspection policy and let underinvoicing occur. Such a threshold $\hat{s}_{1}$ is defined by:

$$
\hat{s}_{1}=\frac{F_{A}-\frac{1-\nu}{\nu} c_{1}}{F_{A}-b_{1} \alpha \Delta q}
$$

One may wonder whether it is possible to decrease the impact of corruption and therefore to increase the payoff of the regulator by using an incentive wage policy at the customs administration, i.e. in our model, by offering to $S_{1}$, a higher wage in case it reports $\bar{q}$. There are several arguments against this kind of solution. First, in our model, information is soft and nothing prevents $S_{1}$ from declaring $\bar{q}$ even if the true value is $\underline{q}$. For the regulator, the costs associated with such a strategy are not explicit in the model. 
However, it is reasonable to think that reputation effects would lead the importing firms to change their plans in the future in reaction to such an extortion and that the regulator would be hurt in the long run. Second, even if information were hard and $S_{1}$ could not forge evidence, it is a well known result that when the contract proposed to the agent cannot be optimally asjusted to information reported by the supervisor (which is the case here because both the rate $\alpha$ and the penalties $F_{A}$ are exogenously fixed), screening of the supervisor is difficult and for a sufficiently small probability $s$, it is optimal to let corruption occur in equilibrium by paying the supervisor a constant wage (see Kofman and Lawarree (1996), for instance).

For further reference, when the regulator chooses to implement inspection by the customs administration with $p_{1}$ defined in equation (3), we denote it the customs-only inspection policy.

\subsection{The PSI game}

Consider now the possibility that the regulator uses another source of information, namely a preshipment inspection firm $S_{2}$. This second supervisor can carry inspection of the merchandises in the exporting country and intervenes before the customs administration. We shall assume that this supervisor is not subject to corruption. When the regulator asks $S_{2}$ to inspect, $S_{2}$ observes the true value of $q$ (costlessly for simplicity) and reports $\tilde{q}_{2}$. The regulator pays it $\beta \tilde{q}_{2}$, where $\beta \in[0 ; \alpha]$. This wage profile is the result of bargaining between the different countries interested in PSI programs and the small number of firms offering this kind of services. We assume for simplicity that it is exogenously fixed. ${ }^{11}$ Even

\footnotetext{
${ }^{11}$ The linearity of $S_{2}$ 's wage profile is assumed to stick with real world practices where $S_{2}$ is paid between 0,5 and $0,8 \%$ of the inspected merchandises value. This assumption could be relaxed. What is actually important for our results is that $S_{2}$ is paid more when it reports $\bar{q}$ than when it reports $q$. This hypothesis could be justified in the first place by the consideration of a moral hazard problem in the delegation of the supervisory task to the PSI firm. For simplicity, we abstract from this moral hazard problem and we simply assume that $S_{2}$ 's wage is linear and increasing.
} 
if this supervisor is not corruptible, the problem with $S_{2}$ comes from the fact that it has an incentive to always exaggerate $\tilde{q}_{2}$ in order to perceive a higher wage. If the regulator uses $S_{2}$ alone, it would not acquire any valuable information on the true value $q$. Therefore, it has to combine inspections by $S_{1}$ and $S_{2}$, taking into account the propensity of $S_{1}$ to minimize $q$, because of corruption, and of $S_{2}$ to exaggerate $q$ because of opportunistic behavior. We assume that in case the regulator is persuaded that $S_{2}$ exaggerated the quantity $\tilde{q}_{2}$, it can impose a fine $F_{S_{2}}>\beta \Delta q$. The second supervisor is risk neutral and maximizes its expected revenue.

The timing is now as follows.

- At date $t=0$, the firm $A$ learns its type $q$,

- At date $t=1, A$ declares $\tilde{q}$ to $R$,

- At date $t=2$, with probability $p_{2}(\tilde{q}), R$ asks $S_{2}$ to inspect the merchandises,

- At date $t=3, S_{2}$ sends a report $\tilde{q}_{2}$,

- At date $t=4$, with probability $p_{1}\left(\tilde{q}, \tilde{q}_{2}\right) R$ asks $S_{1}$ to inspect the merchandises,

- At date $t=5, S_{1}$ and $A$ may collude,

- At date $t=6, S_{1}$ sends a report $\tilde{q}_{1}$ to $R$,

- At date $t=7$, transfers take place.

When a supervisor is not asked to inspect, its report is $\emptyset$ by convention. The instruments available to the regulator are the two contingent probabilities of inspection $\left(p_{1}(\cdot), p_{2}(\cdot)\right)$. Because inspection is costly, it is of course optimal to set $p_{2}(\bar{q})=0$, $p_{1}(\bar{q}, \emptyset)=0$ and $p_{1}(\underline{q}, \underline{q})=0$. The regulator must still choose $p_{2}(\underline{q})=p_{2}, p_{1}(\underline{q}, \bar{q})=p_{1}$ and $p_{1}(\underline{q}, \emptyset)=p_{1}(\emptyset)$. Those endogenous variables characterize what we call the inspection policy. The no inspection policy is one particular case with $p_{1}=p_{2}=0 .{ }^{12}$ The customs-only inspection policy is another particular case with $p_{2}=0$.

\footnotetext{
${ }^{12}$ Even if customs authorities are often reluctant to forget systematic inspections, controls selectivity remains a key component of customs modernization. Geourjon and Laporte (2005) show how a sophisticated risk management method can facilitate trade by rationally selecting transactions, with the end result of actually enhancing revenue performance.
} 
It is also possible for the regulator to choose which parties are to be fined in case of conflicting reports. Of particular importance are the decisions to adopt : first, in case $\tilde{q}=\underline{q}, \tilde{q}_{2}=\bar{q}$ and $\tilde{q}_{1}=\emptyset$, second, in case $\tilde{q}=\underline{q}, \tilde{q}_{2}=\bar{q}$ and $\tilde{q}_{1}=\underline{q}$. Such decisions characterize what we will call the reconciliation policy.

The principle of maximum punishment applies in our context and it would be optimal for the regulator to fine both $A$ and $S_{2}$ in case two reports conflict. However, it would not be realistic to assume that the regulator can implement such a punishment strategy because it would rely on the threat of punishing both parties in case of a conflict between $A$ and $S_{2}$, in other words, the regulator would have to use the same proofs both against $A$ and $S_{2}$. To stick with reasonable practices, we will assume in what follows that the regulator can only punish one party at a time. The reconciliation policy may be stochastic but in any state of the world, the regulator can only fine $A$ or $S_{2}$.

\section{The optimal PSI program}

\subsection{Regular Truthful Equilibrium}

We first characterize the optimal contract that induces truthful reporting in equilibrium, both by $A$ and $S_{2}$.

Suppose in addition that $p_{1}(\underline{q}, \emptyset)=0$ and that $R$ imposes a fine to $A$ when $A$ 's report conflicts with $S_{2}$ 's report, unless $S_{1}$ 's report confirms $A$ 's report. In that latter case (which occurs when $\tilde{q}=\tilde{q}_{1}=\underline{q}$ and $\tilde{q}_{2}=\bar{q}$ ), $R$ imposes a fine to $S_{2}$. In the following, an equilibrium that satisfies these properties will be called a regular truthful equilibrium. ${ }^{13}$

\footnotetext{
${ }^{13}$ Remark that in a regular truthful equilibrium, the fines are imposed only out of equilibrium. They are just threats. This means that honest (equilibrium) behavior is never punished : certainly a desirable property, even if its long term benefits are not modelled here.
} 
The relevant incentive constraint for $A$ can be written

$$
\alpha \Delta q \leq p_{2}\left(\left(1-p_{1} s\right) F_{A}+p_{1} s b_{1} \alpha \Delta q\right)
$$

The right hand side characterizes the expected cost of declaring $\underline{q}$ when $q=\bar{q}$. In that case, the agent is fined $F_{A}$ when $S_{2}$ inspects (which occurs with probability $p_{2}$ in a truthful equilibrium), unless $S_{1}$ inspects also and colludes with $A$ (which occurs with probability $\left.p_{1} s\right)$. When the latter occurs, $A$ must nevertheless pay a bribe $b_{1} \alpha \Delta q$ to $S_{1}$. The left hand side of equation (5) is the benefit of declaring $\underline{q}$.

In a truthful equilibrium, $S_{2}$ must have an incentive not to exaggerate its report if it observes $q=\underline{q}$. The corresponding incentive constraint is

$$
\beta \Delta q \leq p_{1} F_{S_{2}}
$$

the benefit from lying must be less than the expected cost of doing so.

Because inspection is costly, $R$ wants to minimize the probabilities $p_{1}$ and $p_{2}$ and constraints (5) and (6) will bind in equilibrium. ${ }^{14}$

Proposition 2 The optimal regular truthful equilibrium is characterized by the probabilities of inspection

$$
p_{1}^{*}=\frac{\beta \Delta q}{F_{S_{2}}},
$$

and

$$
p_{2}^{*}=\frac{\alpha \Delta q}{F_{A}-\frac{s \beta \Delta q\left(F_{A}-b_{1} \alpha \Delta q\right)}{F_{S_{2}}}} .
$$

\footnotetext{
${ }^{14}$ There is another incentive constraint that we must take into account. Out of equilibrium, if $S_{2}$ observes $\bar{q}$, it must prefer to report the truth rather than $q$. This path of events does not occur in a truthful equilibrium, but we implicitly assume this constraint is satisfied when we wrote equation (5). This additional constraint is

$$
\beta \Delta q \geq p_{1} s F_{S_{2}} .
$$
}

Provided, equation (6) binds, it is automatically satisfied. 
Some comparative statics are illuminating. First, and as intuition suggests, $p_{2}^{*}$ is increasing in $s$ the corruptibility of the customs administration, and decreasing with $F_{A}$, the fine that can be imposed on a dishonest firm. More interestingly, $p_{2}^{*}$ is also decreasing with $F_{S_{2}}$ the fine that can be imposed on a dishonest PSI supervisor. This is so because a higher $F_{S_{2}}$ allows to decrease $p_{1}$, which in turn means that $A$ will have fewer opportunities to collude and escape the penalty $F_{A}$. It is therefore easier to provide incentives to $A$. Finally, $p_{2}^{*}$ is increasing with $\beta$. This means that a badly negotiated PSI program leads to higher costs for two reasons. The first one is a direct effect, a higher $\beta$ means that it is more costly for the regulator to implement a given probability of inspection by $S_{2}$. The second effect is indirect, a higher $\beta$ makes it more difficult to provide incentives to $S_{2}$. It calls for a higher $p_{1}$, which in turns means that $A$ will be more often able to collude. Therefore, inducing truthful reporting by $A$ necessitates a higher $p_{2}$.

Notice that in a regular truthful equilibrium, the customs administration never inspects because $S_{2}$ 's report never conflicts with $A$ 's one. Therefore, the equilibrium value $p_{1}^{*}$ has no direct impact on the regulator's profit. It has only an indirect impact through its influence on $p_{2}^{*}$.

Notice also that implementing the probabilities of inspection characterized in PROPOSITION 2 requires commitment by the regulator. It is well known from the literature on auditing (see Khalil (1997) or Strausz (1997)) that the optimal inspection strategy that can be played with commitment may not be subgame perfect if the regulator could not commit.

\subsection{Optimal inspection policy}

In this section, we check whether implementing the optimal regular truthful equilibrium identified in Proposition 2 is indeed the optimal inspection policy available to the regulator. The regulator faces basically three options. He can decide to implement the 
optimal regular truthful equilibrium identified in Proposition 2, i.e. decide to use the PSI firm ; he can decide to use the customs administration only and implement the inspection policy identified in equation (3); or he can simply choose to let underinvoicing occur and decide to use neither the PSI firm, nor the customs administration. In order to compare the last two options, we already introduced the threshold $\hat{s}_{1}$ defined in equation (4). For the two other pairs of options, we will need

$$
\hat{s}_{2}=\frac{F_{A}-\frac{1-\nu}{\nu} \beta \underline{q}}{\frac{\beta \Delta q}{F_{S_{2}}}\left(F_{A}-b_{1} \alpha \Delta q\right)},
$$

and

$$
\hat{s}_{3}=\frac{F_{A}\left(\frac{\beta \underline{q}}{c_{1}}-1\right)}{\left(F_{A}-b_{1} \alpha \Delta q\right)\left(\frac{\beta \underline{q}}{c_{1}}-\frac{\beta \Delta q}{F_{S_{2}}}\right)} .
$$

Proposition 3 The corruptibility thresholds $\widehat{s}_{1}, \widehat{s}_{2}$ and $\widehat{s}_{3}$ satisfy the following properties:

(i) If $\beta \underline{q} \leqslant c_{1}$, then $\widehat{s}_{1} \leqslant \widehat{s}_{2}$;

(ii) If $\beta \underline{q}>c_{1}$, then the thresholds $\widehat{s}_{1}, \widehat{s}_{2}$ and $\widehat{s}_{3}$ are such that either $\widehat{s}_{3}<\widehat{s}_{1}<\widehat{s}_{2}$ or $\widehat{s}_{2}<\widehat{s}_{1}<\widehat{s}_{3}$, or $\widehat{s}_{1}=\widehat{s}_{2}=\widehat{s}_{3} ;$

The optimal inspection policy is characterized by:

(j) If $\beta \underline{q} \leqslant c_{1}$, the regulator implements the optimal regular truthful equilibrium characterized in Proposition 2 when $s$ is lower than $\widehat{s}_{2}$ and prefers the no inspection policy when $s$ is higher than $\widehat{s}_{2}$.

(jj) If $\beta \underline{q}>c_{1}$ and $\widehat{s}_{3} \leqslant \widehat{s}_{1} \leqslant \widehat{s}_{2}$, the regulator chooses the customs-only inspection policy when $s$ is lower than $\widehat{s}_{3}$, implements the optimal regular truthful equilibrium characterized in Proposition 2 when $\widehat{s}_{3} \leqslant s \leqslant \widehat{s}_{2}$, and prefers the no inspection policy when $s \geqslant \widehat{s}_{2}$, (jjj) If $\beta \underline{q}>c_{1}$ and $\widehat{s}_{2} \leqslant \widehat{s}_{1} \leqslant \widehat{s}_{3}$, the regulator chooses the customs-only inspection policy when $s$ is lower than $\widehat{s}_{1}$, and prefers the no inspection policy when $s \geqslant \widehat{s}_{1}$.

Proof. See the appendix. 
Entering a PSI-program is clearly not optimal for all countries. Proposition 3 clarifies the impact of the different parameters of our model on the desirability of such a program. In case $(j j j)$ for instance, entering a PSI program is always dominated, whatever the degree of corruption of the customs administration. Such a case occurs when $\beta \underline{q}>c_{1}$, i.e. an uncorrupted customs administration would cost less than the PSI firm, and $\beta \Delta q$ is lower but close enough to $F_{S_{2}}$, which means that $S_{2}$ is difficult to incentivize.

If all other things being equal, $F_{S_{2}}$ grows, it is easier to incentivize $S_{2}$ and we turn to case $(j j)$. It is optimal to enter a PSI program for intermediate degrees of corruption of the customs administration. In this case, the customs-only inspection policy is preferred for low degrees of corruption while the no inspection policy is optimal for very high degrees of corruption.

Finally, when the customs administration is very inefficient, with $c_{1}>\beta \underline{q}$, it is never optimal to use the customs-only inspection policy. We are in case $(j)$ and for low degrees of corruption, it is optimal to enter a PSI program, while for high degrees of corruption, the no inspection policy is preferred.

It may be simpler to understand graphically the content of Proposition 3. We draw on Figure 1 the optimal inspection policy in the corruptibility-inefficiency (i.e. $s-c_{1}$ ) plan. To each value of $s$ and $c_{1}$, it associates the preferred policy (i.e. PSI, customs only or no inspection) of the regulator. 


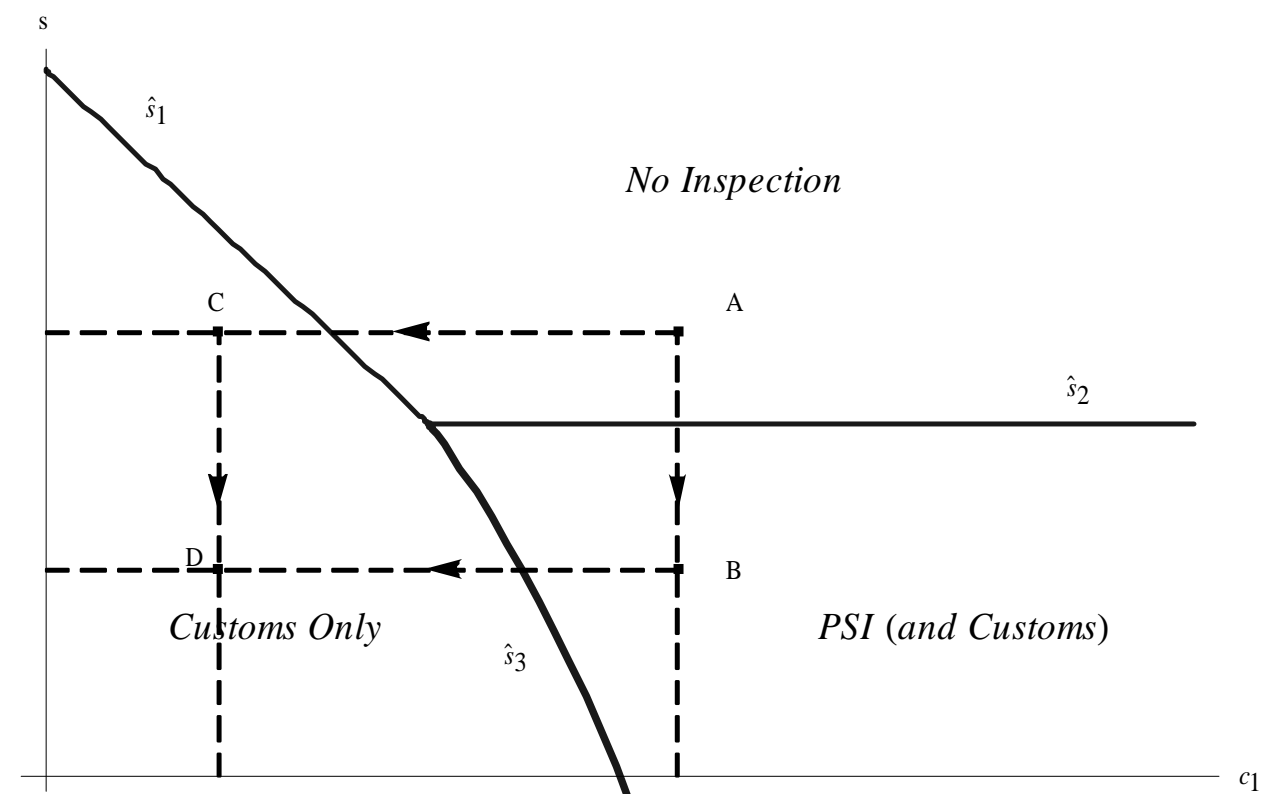

Figure 1: Optimal inspection policy

In this corruptibility-inefficiency plan, a vertical translation to the bottom (from $A$ to $B$ for instance) corresponds to a reduction in the parameter $s$. It can be interpreted as an "ethical" modernization of customs. Depending on the initial situation of the country, a PSI program can become the optimal policy if the customs administration is rather inefficient. If the cost of customs' control $\left(c_{1}\right)$ is sufficiently low (an efficient customs administration), this "ethical" modernization only increases the likelihood that the customs-only inspection policy is optimal. In 1993, in recognition of the significant problems of corruption in customs administrations, the World Customs Organization (WCO) adopted the Arusha Declaration. The declaration sets out the main features that should be present to reduce corruption. Practical measures to promote integrity in customs modernization programs, often designed with international institutions (IMF, World Bank, WCO) technical assistance, aim at providing a framework for changing the incentive structure and for establishing the legal and administrative procedures that are 
necessary to detect, punish, and reduce corruption (Keen (2003); De Wulf and Sokol (2004)).

A horizontal translation to the left (from the point $A$ to $C$ or from $B$ to $D$ for instance) corresponds to a reduction in the parameter $c_{1}$. This move can be interpreted as a technical modernization of customs. Some components of this technical modernization are usually included in PSI proposal by private companies to obtain the contract. Moving from $B$ to $D$ in Figure 1 increases the likelihood that the customs-only inspection policy is optimal. We can then deduce that PSI contract including customs' modernization services are intrinsically inconsistent and therefore inefficient. ${ }^{15}$

Morocco and the Philippines are regarded as two examples of successful customs modernization (see Keen (2003)). In 1996, in Morocco, the average stay of containers in Casablanca was 16 days of which 10 days were attributable to customs controls. After three years, the processing time for customs declarations had fallen from ten days to three hours, and after five years 85 percent of declarations were processed in under an hour and a half, all with no apparent costs in terms of customs revenue collected. In Philippines, despite the huge increase in import volumes-by over 160 percent between 1990 and 1996 - cargo clearance time had fallen from an average of around one week to less than 48 hours for selected shipments and less than 15 minutes for super green lane shipments.

\subsection{Optimal reconciliation policy}

How to reconcile conflicting information provided by the PSI firm and the customs administration is a hotly debated practical issue. Translated in the terms of our model, this amounts to know how the regulator should behave when $\tilde{q}=\tilde{q}_{1}=\underline{q}$ whereas $\tilde{q}_{2}=\bar{q}$ and

\footnotetext{
${ }^{15}$ Moreover, beyond our formalization, customs' modernization yields a direct communication between the PSI firm and the customs administration which may induce a risk of collusion between them.
} 
when $\tilde{q}=\underline{q}, \tilde{q}_{2}=\bar{q}$ and $\tilde{q}_{1}=\emptyset$. Should he fine $A$ because this certainly corresponds to a case of underinvoicing with or without corruption or should he fine $S_{2}$ because this certainly corresponds to an opportunistic strategy of that party? So far we assumed that facing the first situation, the regulator chooses to fine $S_{2}$ while he chooses to fine $A$ when facing the second. Is it truly optimal?

For simplicity, we consider a situation where it is optimal for the regulator to use the two supervisors. Suppose now that when $\tilde{q}=\tilde{q}_{1}=\underline{q}$ whereas $\tilde{q}_{2}=\bar{q}$, the regulator fines $A$ with probability $\mu_{1}$ and fines $S_{2}$ with probability $1-\mu_{1}$.

To keep things comparable, we assume that in this case, the bribe that a dishonest customs officer receives is $\left(1-\mu_{1}\right) b_{1} \alpha \Delta q$, i.e. is $\left(1-\mu_{1}\right)$ times the bribe he received when $\mu_{1}$ was equal to 0.

Suppose also that when $\tilde{q}=\underline{q}, \tilde{q}_{2}=\bar{q}$ and $\tilde{q}_{1}=\emptyset$, the regulator fines $S_{2}$ with probability $\mu_{2}$ and $A$ with probability $1-\mu_{2}$.

In that case, the two relevant incentive constraints for $A$ and $S_{2}$ are respectively

$$
\alpha \Delta q \leq p_{2}\left(\left(1-p_{1}\right)\left(1-\mu_{2}\right) F_{A}+p_{1}(1-s) F_{A}+p_{1} s\left(\mu_{1} F_{A}+\left(1-\mu_{1}\right) b_{1} \alpha \Delta q\right)\right)
$$

and

$$
\beta \Delta q \leq\left(\left(1-p_{1}\right) \mu_{2}+p_{1}\left(1-\mu_{1}\right)\right) F_{S_{2}}
$$

We can rearrange the incentive constraint (7) to obtain:

$$
\alpha \Delta q \leq p_{2} F_{A}\left(1-\left(1-p_{1}\right) \mu_{2}-p_{1}\left(1-\mu_{1}\right)+p_{1}\left(1-\mu_{1}\right)\left(1+s \frac{F_{A}-b_{1} \alpha \Delta q}{F_{A}}\right)\right)
$$

Constraints (8) and (9) are binding at the optimum. $>$ From this we can characterize the two equilibrium probabilities $p_{1}^{*}\left(\mu_{1}, \mu_{2}\right)$ and $p_{2}^{*}\left(\mu_{1}, \mu_{2}\right)$ that minimize the regulator's total inspection costs. From the fact that (8) is binding, we deduce easily that $p_{1}\left(1-\mu_{1}\right) \leq$ 
$\frac{\beta \Delta q}{F_{S_{2}}}$, with equality when $\mu_{2}=0$. We can also rewrite (9) binding as

$$
\alpha \Delta q=p_{2} F_{A}\left(1-\frac{\beta \Delta q}{F_{S_{2}}}+p_{1}\left(1-\mu_{1}\right)\left(1+s \frac{F_{A}-b_{1} \alpha \Delta q}{F_{A}}\right)\right)
$$

from which we deduce that in order to minimize $p_{2}$, the regulator must choose $\mu_{2}=0$, i.e. $p_{1}\left(1-\mu_{1}\right)=\frac{\beta \Delta q}{F_{S_{2}}}$.

Once we know that it is optimal to set $\mu_{2}=0$, the choice of $\mu_{1}$ has no impact on the optimal $p_{2}^{*}$. The only thing that changes is $p_{1}^{*}$ that is higher when $\mu_{1}$ is different from 0 . However, in equilibrium, this has no impact on the regulator's payoff because $S_{1}$ never inspects in a truthful equilibrium. Incentive compatibility nevertheless imposes that $\frac{\beta \Delta q}{F_{S_{2}}\left(1-\mu_{1}\right)} \leq 1$.

Proposition 4 When $S_{2}$ 's inspection technology is perfect, the regulator strictly prefers to always punish $A$ when $\tilde{q}=\underline{q}, \tilde{q}_{2}=\bar{q}$ and $\tilde{q}_{1}=\emptyset$; and he is indifferent between the various incentive compatible reconciliation policies when $\tilde{q}=\tilde{q}_{1}=\underline{q}$ and $\tilde{q}_{2}=\bar{q}$.

In order to discuss more accurately this topic, we modify slightly the model in order to introduce some imperfection in the inspection technology of $S_{2}$. We assume that when $q=\bar{q}$, if $S_{2}$ inspects, it observes $\bar{q}$ with probability 1 , while, if $q=\underline{q}, S_{2}$ observes $\bar{q}$ with probability $\sigma$ and $q$ with probability $(1-\sigma)$ ( $\sigma$ being small). Here again we are interested in determining the reconciliation policy that minimizes the expected inspection costs and that induces truthful reporting by $A$ and $S_{2}$ on the equilibrium path. With this information structure and for $\sigma$ sufficiently small, the incentives are not changed. Indeed, for the agent, the relevant incentive constraint is still the one that states that a $\bar{q}$-agent should not prefer to declare $\underline{q}$. In this state of nature, the inspection technology is actually perfect and the constraint is exactly the same as before : it is equation (7). 
Concerning the second supervisor $S_{2}$, when he observes $\underline{q}$, he knows for sure that the true value of $q$ is $\underline{q}$, and he anticipates that if the customs administration inspects the merchandises, it will discover that the true value is $\underline{q}$ with probability 1 . Therefore, the incentive constraint of a supervisor $S_{2}$ that observes $\underline{q}$ and considers the possibility of reporting $\bar{q}$ is again the same as before: it is equation (8). For the second supervisor, the imperfection in the inspection technology could have an impact on the other incentive constraint : the one that states that when $S_{2}$ observes $\bar{q}$, it prefers to report $\bar{q}$ rather than $\underline{q}$. However, this constraint was not binding in equilibrium when $\sigma=0$, i.e. with a perfect inspection technology, and will not be binding either for $\sigma$ sufficiently small, as a simple continuity argument shows.

The only difference is that, with an imperfect inspection technology, inspection by $S_{1}$ occurs with a positive probability on the equilibrium path. On the equilibrium path, $A$ reports $\underline{q}$ with probability $1-\nu$, and this is followed by a truthful report $\bar{q}$ by $S_{2}$ with probability $\sigma$. Inspection by $S_{1}$ therefore occurs with the ex ante probability $(1-\nu) \sigma p_{1}$. In this case, the regulator strictly prefers a reconciliation policy that minimizes $p_{1}$ all other things being equal.

Proposition 5 When $S_{2}$ 's inspection technology is imperfect, the regulator minimizes the inspection costs while ensuring truthful reporting by $A$ and $S_{2}$ when he implements the reconciliation policy that is favorable to the exporting firm when $\tilde{q}=\tilde{q}_{1}=\underline{q}$ and $\tilde{q}_{2}=\bar{q}$.

The result stated in Proposition 5 may seem counterintuitive because PSI programs are used to fight corruption in the customs administration and one could think that $S_{2}$ 's report is more reliable than $S_{1}$ 's report.

It is important to realize that the optimality of a reconciliation policy that is unfavorable to $S_{2}$ is an equilibrium phenomenon, i.e. it is true if the regulator designs carefully all other aspects of the program. 
The intuition is that, in equilibrium, inspection by the customs administration is used to discipline the opportunistic supervisor $S_{2}$ and not directly to discipline the agent. Moreover, in our model, corruption of the customs administration is supposed not to occur in equilibrium if $S_{2}$ is used sufficiently frequently. Actually, with an imperfect inspection technology, corruption and underinvoicing are controlled through the reconciliation policy implemented when $\tilde{q}=\underline{q}, \tilde{q}_{2}=\bar{q}$ and $\tilde{q}_{1}=\emptyset$, while the oppportunisitc behavior of $S_{2}$ is controlled through the reconciliation policy implemented when $\tilde{q}=\tilde{q}_{1}=\underline{q}$ and $\tilde{q}_{2}=\bar{q}$. This explains why it is optimal to believe $S_{2}$ when $\tilde{q}=\underline{q}, \tilde{q}_{2}=\bar{q}$ and $\tilde{q}_{1}=\emptyset$, and to believe $A$ when $\tilde{q}=\tilde{q}_{1}=\underline{q}$ and $\tilde{q}_{2}=\bar{q}$.

\section{Conclusion}

In this paper we provide, to the best of our knowledge, the first normative study of Pre-Shipment Inspection Programs that is built upon a completely specified hierarchical agency model. This model allowed us to better understand the linkages existing between the different incentives that can be provided to the importing firms and those that can be provided to PSI firms. The model also highlighted how important it is, for their profitability, to carefully design different aspects of PSI programs such as the commitment to an inspection policy or to a reconciliation policy. More generally, our model is useful to understand the mechanics of mutual supervision in hierarchical agency models with multiple supervisors.

Entering a PSI program is not optimal for all countries. In particular, as we showed in Proposition 3 , when the level of corruption in the customs administration is too high, it may be preferable to simply let underinvoicing occur. For those countries with high level of corruption, PSI programs are not the solution and it may be preferable to tackle the customs corruption problem more directly. By contrast, under a critical level 
of corruption and above a customs' cost of control, the PSI programs are optimal and then justified. However, we have also established that the customs' modernization and corruption control are conflicting objectives and must not be assigned to the same private firm. An improvement for future programs concerning customs in developing countries would be to distinguish these two objectives and address them with two different contracts. 


\section{References}

Anson, J., O. Cadot, and M. Olarreaga (2006): "Tariff Evasion and Customs Corruption: Does Pre-Shipment Inspection Help?," Contributions to Economic Analysis 8 Policy, 5(1), 1600-1600.

BAC, M., AND P. K. BAG (2006): "Beneficial collusion in corruption control: The case of nonmonetary penalties," Journal of Development Economics, 81(2), 478-499.

Bhagwati, J. (1964): "On the Undervoicing of Imports," Oxford Bulletin of Economics and Statistics, 26(4), 389-97.

Bolton, P., and M. Dewatripont (2005): Contract theory. Cambridge, Mass., Mit Press.

DE Wulf, L. (1981): "Statistical analysis of under- and overinvoicing of imports," Journal of Development Economics, 8(3), 303-323.

De Wulf, L., And J. Sokol (2004): Customs Modernization Handbook. World Bank Publications, Whashington, DC.

Fisman, R., And S.-J. Wei (2004): "Tax Rates and Tax Evasion: Evidence from "Missing Imports" in China," Journal of Political Economy, 112(2), 471-500.

Geourjon, A.-M., And B. Laporte (2005): "Risk Management for Targeting Customs Controls in Developing Countries: A Risky Venture for Revenue Performance?," Public Administration and Development, 25, 105-113.

Hoekman, B., And A. Nicita (2008): "Trade Policy, Trade Costs and Developing Country Trade," Policy Research Working Paper 4797, The World Bank. 
Johnson, N. (2001): "Committing to civil service reform : the performance of preshipment inspection under different institutional regimes," Policy Research Working Paper Series 2594, The World Bank.

Keen, M. (2003): Changing Customs: Challenges and Strategies for the Reform of Customers Administration. International Monetary Fund, Whashington, DC.

Khalil, F. (1997): "Auditing without Commitment," RAND Journal of Economics, $28(4), 629-640$.

Kofman, F., And J. Lawarree (1993): "Collusion in Hierarchical Agency," Econometrica, 61(3), 629-56.

(1996): "On the optimality of allowing collusion," Journal of Public Economics, $61(3), 383-407$.

Laffont, J.-J., And D. Martimort (2001): The Theory of Incentives : The PrincipalAgent Model. Princeton University Press.

Low, P. (1995): "Preshipment Inspection Services," World Bank - Discussion Papers 278, World Bank.

Mishra, A., And T. Anant (2006): "Activism, separation of powers and development," Journal of Development Economics, 81(2), 457-477.

Nuinkeu, D., J. Wilson, and B. Powo Fossa (2008): "Expanding Trade within Africa," Policy Research Working Paper 4790, The World Bank.

Pritchett, L., and G. Sethi (1994): "Tariff Rates, Tariff Revenue, and Tariff Reform: Some New Facts," World Bank Economic Review, 8(1), 1-16.

Strausz, R. (1997): "Delegation of Monitoring in a Principal-Agent Relationship," Review of Economic Studies, 64(3), 337-57. 
Tirole, J. (1986): "Hierarchies and Bureaucracies: On the Role of Collusion in Organizations," Journal of Law, Economics and Organization, 2(2), 181-214.

- (1992): Collusion and the Theory of Organizationsvol. Sixth World Congress of Advances in Economic Theory, pp. 151-206. Elsevier.

Wilson, J. S., C. L. Mann, and T. Otsuki (2005): "Assessing the Benefits of Trade Facilitation: A Global Perspective," The World Economy, 28(6), 841-871.

YAnG, D. (2008): "Can Enforcement Backfire? Crime Displacement in the Context of Customs Reform in the Philippines," Review of Economics and Statictics, 90(1), 1-14. (2009): "Integrity for Hire: An Analysis of a Widespread Program for Combating Customs Corruption," Journal of Law, Economics and Organization, Forthcoming. 


\section{A A Proof of Proposition 3}

First, let us compare what the regulator obtains in a regular truthful equilibrium and what he obtains if he decides simply not to ask for inspection and let underinvoicing occur. Absent any inspection, the expected loss is $\nu \alpha \Delta q$, while the expected gains come from what is saved in terms of the inspection costs $(1-\nu) \beta q p_{2}^{*}$. Accordingly, we can define a threshold $\hat{\beta}$ over which the regulator prefers to let underinvoicing occur, i.e. prefers to set $p_{2}=p_{1}=0$. Straight forward computations give the characterization

$$
\hat{\beta}=\frac{F_{A}}{\frac{1-\nu}{\nu} \underline{q}+\frac{s \Delta q}{F_{S_{2}}}\left(F_{A}-b_{1} \alpha \Delta q\right)} .
$$

It is easily seen that $\hat{\beta}$ is decreasing with $s$. Equivalently, it is possible to define a threshold $\hat{s}_{2}$ for the corruptibility of the customs administration. Above that threshold, optimal inspection by the PSI firm is too costly and the regulator prefers not to inspect at all the merchandises.

$$
\hat{s}_{2}=\frac{F_{A}-\frac{1-\nu}{\nu} \beta \underline{q}}{\frac{\beta \Delta q}{F_{S_{2}}}\left(F_{A}-b_{1} \alpha \Delta q\right)} .
$$

The corresponding intuition is that when the degree of corruption of the customs administration grows, inspection by the PSI firm must be more frequent in order to prevent underinvoicing and this is more costly for the regulator who prefers, more often, to let underinvoicing occur. Next, we check when it is optimal for the regulator to fix $p_{1}(\emptyset)=0$.

In other words, we check when it is optimal to use inspection by the customs administration for the sole purpose of providing a disciplining device for the PSI firm . When $p_{1}(\emptyset)$ is different from 0 , in a truthful equilibrium, constraint (6) must still hold and will be binding in equilibrium. Taking this into account, the incentive constraint corresponding 
to (5) is written now

$$
\alpha \Delta q \leq p_{2}\left(F_{A}-\frac{s \beta \Delta q}{F_{S_{2}}}\left(F_{A}-b_{1} \alpha \Delta q\right)\right)+\left(1-p_{2}\right) p_{1}(\emptyset)\left(F_{A}-s\left(F_{A}-b_{1} \alpha \Delta q\right)\right)
$$

The left hand side is, as before, the benefit of a firm that declares $\underline{q}$ instead of the true value $\bar{q}$. The right hand side is the associated cost of doing so. With probability $p_{2}, S_{2}$ inspects the merchandises and discovers the lie; the firm is then fined and pays $F_{A}$, unless $S_{1}$ is also asked to inspect and colludes with $A$ to contradict $S_{2}$ 's report. This latter event occurs with probability $p_{1}^{*} s$ (where $p_{1}^{*}$ is given by equation (6) binding) and leads $A$ to pay $b_{1} \alpha \Delta q$ instead of $F_{A}$. With probability $\left(1-p_{2}\right) p_{1}(\emptyset), S_{1}$ carries the unique inspection of the merchandises and $\mathrm{A}$ is fined unless $S_{1}$ is corruptible, this case corresponds to the second term in the right hand side. In a truthful equilibrium, the objective of the regulator is to minimize the inspection costs given by

$$
(1-\nu)\left(p_{2} \beta \underline{q}+\left(1-p_{2}\right) p_{1}(\emptyset) c_{1}\right)
$$

subject to constraint (11). Let us label $x$ the variable $p_{2}$ and $y$ the variable $\left(1-p_{2}\right) p_{1}(\emptyset)$. It is easily seen that both the objective function and the constraint are linear in $x$ and $y$. Due to this linearity of the objective and the constraint, we conclude that the solution will be in a corner, i.e. either $x=0$ or $y=0$ which implies that either $p_{2}$ will be set equal to zero or $p_{1}(\emptyset)$ will be set equal to zero. The regulator will either choose to use $S_{2}$ and then will set $p_{1}(\emptyset)=0$ or will choose not to use $S_{2}$ and to rely only on $S_{1}$, the customs administration. More precisely, the regulator chooses to set $p_{1}(\emptyset)=0$ when

$$
\beta \underline{q}<c_{1}\left(\frac{F_{A}-\frac{s \beta \Delta q}{F_{S_{2}}}\left(F_{A}-b_{1} \alpha \Delta q\right)}{F_{A}-s\left(F_{A}-b_{1} \alpha \Delta q\right)}\right)
$$

while he chooses to set $p_{2}=0$ in case of a strict reverse inequality. If the left and 
the right hand sides in (12) are equal, he is indifferent between the different inspection policies as long as (11) is binding. It can easily be seen that equation (12) is satisfied for all admissible values of the parameters as soon as $\beta \underline{q}<c_{1}$, i.e. as soon as the PSI firm is less costly than an uncorrupted customs administration. However, it can still be satisfied when the reverse inequality holds, $\beta q>c_{1}$, i.e. when the PSI firm is more costly than an uncorrupted customs administration. If we want to isolate the impact of $\mathrm{s}$, the corruptibility of the customs administration, on the choice of th regulator, we can equivalently state that the regulator chooses to set $p_{2} \neq 0$, i.e. chooses to use the PSI firm when

$$
F_{A}\left(\frac{\beta \underline{q}}{c_{1}}-1\right)<s\left(\frac{\beta \underline{q}}{c_{1}}-\frac{\beta \Delta q}{F_{S_{2}}}\right)\left(F_{A}-b_{1} \alpha \Delta q\right) .
$$

This last inequality will have different consequences, depending on the signs of $\left(\frac{\beta \underline{q}}{c_{1}}-1\right)$ and $\left(\frac{\beta \underline{q}}{c_{1}}-\frac{\beta \Delta q}{F_{S_{2}}}\right)$. Before stating Proposition, let us define a third threshold for $s$, namely $\hat{s}_{3}$ by

$$
\hat{s}_{3}=\frac{F_{A}\left(\frac{\beta \underline{q}}{c_{1}}-1\right)}{\left(F_{A}-b_{1} \alpha \Delta q\right)\left(\frac{\beta \underline{q}}{c_{1}}-\frac{\beta \Delta q}{F_{S_{2}}}\right)} .
$$

We are now ready to establish the proposition. Property $(i)$ is an immediate consequence of the expressions of $\widehat{s}_{1}$ and $\widehat{s}_{2}$. To prove $(i i)$, observe that the right hand side of equation (12) is increasing in $s$ and that this strict inequality is verified for $\widehat{s}_{1}$ if and only if $\widehat{s}_{1}<\widehat{s}_{2}$. Therefore, we know that $\widehat{s}_{3}<\widehat{s}_{1} \Longleftrightarrow \widehat{s}_{1}<\widehat{s}_{2}$, which is equivalent to $(i i)$. Properties $(j)$, $(j j)$ and $(j j j)$ are direct consequences of the analysis we conducted so far. 


\section{B Tables}

Table 1: PSI Programs for Customs purposes (Revenue Protection)

\begin{tabular}{|c|c|c|}
\hline Country & $\begin{array}{l}\text { Mandated Member(s) of } \\
\text { IFIA PSI Committee }\end{array}$ & Basis of Member Choice \\
\hline Angola & BIVAC, Cotecna, SGS & Importer \\
\hline Bangladesh & $\begin{array}{l}\text { BIVAC, Intertek, } \\
\text { SGS, OMIC }\end{array}$ & Geographical \\
\hline Benin & BIVAC & Monopoly \\
\hline Burkina Faso & Cotecna & Monopoly \\
\hline Cambodia & BIVAC & Monopoly \\
\hline Central African Rep. & BIVAC & Monopoly \\
\hline Chad & BIVAC & Monopoly \\
\hline Congo & Cotecna & Monopoly \\
\hline Dem. Rep. Congo & BIVAC & Monopoly \\
\hline Iran & $\begin{array}{c}\text { BIVAC, Cotecna, Intertek, } \\
\text { SGS, OMIC }\end{array}$ & Importer \\
\hline Mauritania & SGS & Monopoly \\
\hline Niger & Cotecna & Monopoly \\
\hline Uzbekistan & $\begin{array}{c}\text { CU International, Intertek, } \\
\text { OMIC, SGS }\end{array}$ & Importer/Exporter \\
\hline
\end{tabular}

Source: International Federation of Inspection Agencies (IFIA), January 2009. 
Table 2: Customs Support Services (including Destination inspection and/or Selective PSI)

\begin{tabular}{|c|c|c|}
\hline Country & $\begin{array}{c}\text { Mandated Member(s) of } \\
\text { IFIA PSI Committee }\end{array}$ & Basis of Member Choice \\
\hline Burundi & SGS & Monopoly \\
\hline Cameroon & SGS & Monopoly \\
\hline Comoros & Cotecna & Monopoly \\
\hline Cote d'Ivoire & BIVAC & Monopoly \\
\hline Equatorial Guinea & Cotecna & Monopoly \\
\hline Ghana & BIVAC, Cotecna & Air \& land-/sea-freight \\
\hline Guinea(Conakry) & BIVAC & Monopoly \\
\hline Haiti & SGS & Monopoly \\
\hline Liberia & BIVAC & Monopoly \\
\hline Mali & BIVAC & Monopoly \\
\hline Mozambique & Intertek & Monopoly \\
\hline Nigeria & Cotecna, SGS & Port of Arrival \\
\hline Senegal & Cotecna & Monopoly \\
\hline Sierra Leone & Intertek & Monopoly \\
\hline Tanzania & Cotecna & Monopoly \\
\hline Togo & Cotecna & Monopoly \\
\hline
\end{tabular}

Source: International Federation of Inspection Agencies (IFIA), January 2009. 
Table 3: Revenues of the four biggest firms on the PSIs market in 2007. Total Revenues PSI Revenues

\begin{tabular}{lcc} 
& millions $\$$ & millions $\$$ \\
\hline SGS $\left(^{*}\right)$ & 3751 & 182 \\
\hline BIVAC & 2637 & 208 \\
\hline Intertek & 1095 & 74 \\
\hline Cotecna & 216 & 195 \\
\hline Total & 7699 & 658
\end{tabular}

Sources: Union des Banques Suisses (UBS) and Safra Bank (Lux.) Estimations.

(*): Sociéte Générale de Surveillance. From 1991 until 1997, Cotecna was an affiliated firm of SGS. 